If the reviewer's memory serves him, he recalls that in the preface to the first edition of this book the author referred to the difficulty in determining what really constitutes an advance; the difficulty remains, and only time will reveal how much of the vast labnur here recorded will help us in the treatment of our patients. As a record of the painstaking research which is going on in the subjects outlined above, the book is beyond praise; if criticism be not ungracious, however, one must record that a little more space might have been given to clinical subjects such as, for instance, keratoplasty - to mention but one. Fully to appreciate a large section of this volume one would have to be a more knowledgable physicist, physiologist and biochemist than are most practising ophthalmologists, though it is appreciated that such a remark may convey a comment more upon the reader than upon the book, which is a most valuable work and an essential possession of all ophthalmologists who must keep abreast of the research underlying their specialty. The index-an important feature-is adequate, the reference lists comprehensive; the photographic and microphotographic reproductions should indicate the magnification they employ.

F.W.L.

\section{TRANSACTIONS OF THE XIIth BRITISH CONGRESS OF OBSTETRICS AND GYNAECOLOGY, 1949}

Pp. 304, illustrated. London: The Austral Press. 1950. 50 .

This bound volume of the "Transactions of the reth British Congress of Obstetrics and Gynaecology ' will be of greatest interest to those who were able to attend the Congress, but will be widely read by gynaecologists who were unhappily unable to attend, and also by candidates for higher obstetric and gynaecological qualifications.

Many happy and interesting hours will be recalled for those who attended the Congress, and they will perhaps remember most clearly Meig's paper on endometriosis, Prof. George Pickering's brilliant account of essential hypertension in pregnancy and Ayre's explanation of the value of cytology in the diagnosis of uterine cancer. (All will remember with gratitude being able to read these and the other opening discussions in print before their formal presentation at the Congress. Other scientific meetings would do well to adopt the policy of distribution of opening papers before presentation.)

For those who were prevented from attending the Congress there is here an essay to suit every taste, varying from Swyer's endocrinological contribution on pregnandiol essays to Read's surgical contribution on hernia of the pouch of Douglas and Brunschwig's description of pelvic exenteration.

The examination candidate can ill afford to neglect any of these contributions and, indeed, it is unlikely that he would wish to do so.

'This book is altogether a delightful reminder of a happy and profitable Congress.

\section{THE CONQUEST OF MALARIA}

By Dr. J. Jaramillo-Arango. Pp. xiv + 125, with 37 illustrations. London: W. Heinemann. 1950. 2Is."

This book is obviously a labour of love, and the author is to be congratulated on his historical accuracy and erudition. He has exploded several myths and has given an eminently fair presentation as to the exact role played by the numerous pioneers in the elucidation and treatment of the most important of the parasitic diseases that affect mankind.

Part II is a critical review of the basic facts in the history of cinchona. To this section the author has devoted 55 pages out of a total of 125 , and has allowed his enthusiasm to outweigh his sense of proportion to the boredom of the general reader, although the medical historian will ever be in his debt.

The style is attractive and easy to read, and the book is sumptuously produced and well illustrated. It will be appreciated by the medical historian and the malariologist, but not by the general practitioner.

T.C.M.

\section{DAWSON OF PENN}

\section{A Biography}

By Francis Watson. Pp. viii +344 , with I illustration. London: Chatto \& Windus. 1950: I8s.

This account of the life of Lord Dawson of Penn will take a high place among the more notable medical biographies. Written primarily for the general reader it is of especial interest to those who knew Lord Dawson and to the medical profession in general. So adroitly are medical references assembled that one wonders if the writer has had a medical training, though the reference to Archbishop Lang as suffering from ' $\mathrm{fifth}$ nerve' makes the assumption rather unlikely.

Dawson's superb humanity - and the word is scarcely too strong-and his concern for every aspect of his patient's condition is most successfully dealt with, and a worthy picture is presented of his unusual grasp of a patient's entourage as well as of his personality. Indeed Dawson had an almost uncanny instinct in summing up the character, upbringing and achievement of those who consulted him and carried into practice his constant plea that a doctor. must take phenomena of the mind as well as of the body into full consideration. An insight is obtained of his manner of dealing with patients by the inclusion of passages from Dawson's letters to doctors referring patients to him for an opinion. These form a valuable model of what such letters are capable of being. A well-known doctor who ' received through the years opinions upon patients from most of the able consultants in London and other parts of Britain ' puts it on record that " those of Lord Dawson in general medicine were among the foremost in modern scientific accuracy as well 